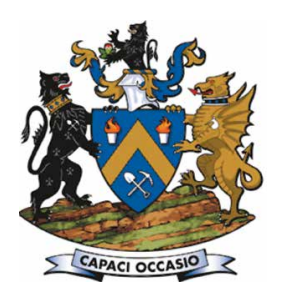

Affiliation:

1Department of Mining, Industrial and ICT Engineering, Polytechnic University of Catalonia, Spain.

Correspondence to:

M. Bascompta

Email:

marc.bascompta@upc.edu

Dates:

Received: 8 Apr. 2019

Revised: 7 Jul. 2019

Accepted: 29 Jul. 2019

Published: October 2019

\section{How to cite:}

Bascompta, M., Sanmiquel, L., Anticoi, H.F., and Oliva, J.

Ventilation friction factor determination and comparison:

Two case studies of potash mining.

The Southern African Insitute of Mining and Metallurgy

DOI ID:

http://dx.doi.org/10.17159/24119717/707/2019

ORCiD ID:

M. Bascompta

https://orchid.org/0000-0003-

1519-6133

L. Sanmiquel

https://orchid.org/0000-0001-

5612-4713

H.F. Anticoi

https://orchid.org/0000-00034316-5203

J. Oliva

https://orchid.org/0000-00016214-5713

\title{
Ventilation friction factor determination and comparison: Two case studies of potash mining
}

\author{
M. Bascompta1', L. Sanmiquel'1, H.F. Anticoi ${ }^{1}$, and J. Oliva1
}

\begin{abstract}
Synopsis
Friction factor is a crucial parameter in assessing and modelling ventilation systems in underground mining. However, the development of a mine along its life-cycle can complicate the airflow supply required at the working faces, creating setbacks in terms of productivity and production. Hence, it is very important to determine all the ventilation parameters, including roughness and the friction factor. In this paper we examine the data from several surveys that were carried out in two potash mines (both using the room-and-pillar method) with the aim of determining the friction factors through the Von Kármán equation, which connects the Atkinson friction factor with airway roughness. Comparison of the two mines provided consistent results, despite some differences in the mining methods, and we were able to establish standard values for this type of mining. Furthermore, a roughness variation over a year in this type of evaporitic mining has been determined, indicating that the specific climate characteristics of the zone affect the walls and roofs of the tunnels and therefore their roughness. Friction factor values have also been validated by means of several ventilation simulations and contrasted with values in the literature.
\end{abstract}

\section{Keywords}

mine ventilation, friction factor, potash mining, roughness.

\section{Introduction}

Knowing the ventilation characteristics is crucial for determining the most effective ventilation circuit and for enhancing the efficiency ratios and saving energy, especially with the trend toward deeper ore deposits and gradually decreasing ore grades (Kazakov, Shalimov, and Kiryakov, 2013; Sasmito et al., 2013; du Plessis, Marx, and Nell, 2014; Hurtado et al., 2014; Develo, Pillalamarry, and Garab, 2016). Airway characteristics and obstacles (e.g., conveyors, machines, or other equipment) determine the airflow behaviour and the resistance the mine presents to airflow. Therefore, knowing these is crucial for modelling ventilation circuits (Shalimov, 2011) and for planning long-term airflow requrements. One of the most important aspects to consider is the friction factor, which is dependent on the geometrical characteristics of the tunnels, the mining method, and the physical condition of the mine (Duckworth and Prosser, 1997; Alymenko, 2012). This friction factor is also a function of the roughness of the airways which, together with obstacles in the ventilation circuit (e.g., conveyor belts or doors), will create resistance to airflow.

The currently available information is mainly focused on coal and metal mines. McElroy (1935) published one of the first studies in this field based on pressure loss values collected from several mines. These values have been used for a long time, with only some changes in the case of coal mining by Kharkar, Stefanko, and Ramani (1974), who pointed out the influence of support and lining on the friction factors. The problem with these values is that current mine openings are much larger and the equipment used is completely different. Therefore, several studies have extended this information, taking into account the evolution of the sector over time (Wala, 1991; Hartman, 1997; Prosser and Wallace, 1999, 2002; Fytas and Gagnon, 2008; Jase and Sastry, 2008; Duckworth, Loomis, and Prosser, 2012), establishing an important database, but without specific values for potash mining.

In this paper we determine the friction factors for two underground mines using continuous mining machines and the room-and-pillar method. As will be seen in the following sections, this type of mining has intrinsic characteristics that influence the roughness of the drifts and consequently the ventilation system. Once the friction factors have been determined, a model of the ventilation circuit in each mine is formulated in order to verify the results by means of ventilation software. 


\section{Ventilation friction factor determination and comparison: Two case studies of potash mining}

\section{Theoretical background}

The square law (Equation [1]) is the basic expression used to investigate the airflow behaviour in underground mines (Hall, 1981; Meyer, 1998; McPherson, 1993; Diego et al., 2011), which relates the concepts of pressure, airflow, and resistance to the passage of air through an airway.

$$
\Delta P=R \cdot Q^{n}
$$

where:

$\Delta P$ is pressure difference $(\mathrm{Pa})$

$R$ is Atkinson's resistance $\left(\mathrm{Ns}^{2} / \mathrm{m}^{8}\right)$

$Q$ is amount of airflow $\left(\mathrm{m}^{3} / \mathrm{s}\right)$

$n$ is a value that varies from unity in laminar regimes to 2.05

in fully turbulent conditions (dimensionless).

The cases studied were always in turbulent conditions, as explained in the subsequent paragraphs. The pressure difference in an airway is a function of the resistance, characteristics of the tunnel, obstacles, and quantity of air flowing through that airway. This difference can be calculated directly, by carrying out a survey with a gauge-tube system or a barometer, or indirectly, by measuring the airflow and the characteristics of the airways, such as roughness (McPherson, 1993). This study is based on the indirect method.

Friction factors, which are determined by the roughness of the tunnels, produce a pressure drop that influences the airflow quantity. These values can be obtained using Equation [2], which is a form of the Chézy-Darcy expression:

$$
p=f L \frac{P e r}{A} \rho \frac{u^{2}}{2}(\mathrm{~Pa})
$$

where

$f \quad$ is coefficient of friction (dimensionless)

$\mathrm{Per}$ is airway perimeter (m)

$A$ is the cross-sectional area $\left(\mathrm{m}^{2}\right)$

$\rho \quad$ is air density $\left(\mathrm{kg} / \mathrm{m}^{3}\right)$

$u$ is air velocity $(\mathrm{m} / \mathrm{s})$

$L \quad$ is length of the airway (m).

Subsequently, Equation [2] was adapted to yield the wellknown Atkinson equation (Equation [3]), expressed as frictional pressure drop . The equivalent length is used to take into account any permanent obstacle found in the airway.

$$
p=k \cdot\left(L+L_{e q}\right) \frac{P e r}{A} u^{2}(\mathrm{~Pa})
$$

where

$k \quad$ is the Atkinson friction factor $\left(\mathrm{kg} / \mathrm{m}^{3}\right)$

$L_{e q}$ is equivalent length (m).

The same equation can also be expressed in terms of resistance using the square law (Equation [4]), and considering any variation in air density inside the mine due to pressure or temperature factors (Montecinos and Wallace, 2010).

$$
R=\frac{p}{Q^{2}}=k \cdot\left(L+L_{e q}\right) \frac{P e r}{A^{3}} \frac{\rho}{1.2}\left(\mathrm{Ns}^{2} / \mathrm{m}^{8}\right)
$$

The Atkinson friction factor is not a constant value; it varies depending on the Reynolds number. However, the airflow in the vast majority of underground places is turbulent in nature, except in a few cases such as behind stoppings or some leakages (McPherson, 1993). Thus, it has been considered as always turbulent in this paper.
Von Kármán’s equation provides a relationship between the coefficient of friction and the friction factor from Atkinson's expression for turbulent flows by means of the drift characteristics. Equation [5] is applicable to circular and noncircular airways by means of the hydraulic mean diameter and is expressed as follows: $D_{h}=4 \mathrm{~A} / \mathrm{Per}$, where $A$ is the cross-sectional area $\left(\mathrm{m}^{2}\right)$ and Per the perimeter $(\mathrm{m})$.

$$
f=\frac{2 k}{\rho}=\frac{1}{4 \cdot\left[2 \cdot \log _{10\left(\frac{D_{h}}{e}\right)+1.14}\right]^{2}} \text { (dimensionless) }
$$

where

$D h$ is the hydraulic mean diameter of the tunnel (m)

$e \quad$ is the height of the roughening $(\mathrm{m})$.

\section{Data collection and methodology}

Determination of the friction factors requires a database of the characteristics of the airways (Meyer, 1998). Thus, several points from the ventilation circuits in both mines have been selected to represent the airways and ventilation conditions. For this purpose, some friction factors in potash mines from the literature have been used (Bascompta, Sanmiquel, and Oliva, 2014), as well as a database system that was created with additional data collected in situ (Bascompta, Sanmiquel, and Oliva, 2015).

Once the points were chosen, all of them were given an identification number with the date and coordinates inside the mine. Five measurements of roughness were performed at each point every time, using a tape measure. Afterwards, the mean roughness values were classified according to the four seasons of the year. Overall, the drift characteristics have been measured over five years.

In addition, the cross-section and air velocity at each point were also measured to model the ventilation circuit. A rotating vane anemometer was used to obtain the mean velocity, and the cross-section was acquired by means of a laser distance measurement. Drift information such as length, obstacles, shape of the airway, and directional variations were also recorded.

Apart from the parameters collected, the mean values of perimeter, hydraulic diameter, and coefficient of friction at each control point were determined. The nomenclature used to identify the points is based on the information provided by the mines, and their number varies depending on the different ventilation layouts.

In order to facilitate the understanding and processing of the data, the mines are distinguished as Mine1 and Mine2 from here on.

\section{Results}

All data from both mines (Mine1 and Mine2) was processed separately, and then the outcomes were compared both between Mine1 and Mine 2 and with other types of mining. The results for both mines are displayed by season and globally, with their corresponding standard deviations. Finally, the results were validated by means of modelling the ventilation system using the VnetPro software (SRK Consulting, Fresno, USA).

\section{Mine1}

Table I shows the mean values used to calculate the friction factors, with special focus on the coefficient of friction $(f)$, which is a function of the other parameters in the table. These values were measured in situ or calculated using the data 


\section{Ventilation friction factor determination and comparison: Two case studies of potash mining}

collected and the equations previously detailed. Airway features were adopted from Bascompta, Sanmiquel, and Oliva (2015).

The values displayed in Table II correspond to the mean friction factors per season and average values per point, considering the four-season values at each key point and their standard deviations (Box et al., 2005 ).

It should be pointed out that there are no results for points $A$ and $\mathrm{D}$ in the summer, because the ventilation circuit was partially modified and there is insufficient representative data for these points.

\section{Mine2}

Tables III and IV detail the coefficients of friction, friction factors per season, and other parameters necessary to calculate the average friction factor at each point. The procedure followed was the same as that described in the previous subsection.

\section{Comparison of outcomes}

Initially, there was a significant difference $(56.8 \%)$ between the

\begin{tabular}{|c|c|c|c|c|c|}
\hline Point & $A\left(\mathrm{~m}^{2}\right)$ & $\operatorname{Per}(\mathrm{m})$ & $D_{h}(\mathrm{~m})$ & $e(m)$ & $f$ \\
\hline 0 & 40.00 & 24.60 & 6.50 & 0.363 & 0.01880 \\
\hline 1 & 34.54 & 24.09 & 5.74 & 0.149 & 0.01345 \\
\hline 2 & 31.84 & 22.60 & 5.64 & 0.144 & 0.01336 \\
\hline 3 & 34.04 & 23.22 & 5.86 & 0.133 & 0.01273 \\
\hline 4 & 27.86 & 21.85 & 5.10 & 0.110 & 0.01250 \\
\hline 5 & 34.80 & 23.24 & 5.99 & 0.142 & 0.01296 \\
\hline 6 & 28.37 & 21.50 & 5.28 & 0.233 & 0.01687 \\
\hline 7 & 23.86 & 17.50 & 5.45 & 0.238 & 0.01676 \\
\hline 8 & 31.54 & 25.00 & 5.05 & 0.119 & 0.01295 \\
\hline 9 & 32.29 & 23.09 & 5.59 & 0.300 & 0.01845 \\
\hline 10 & 27.83 & 22.03 & 5.05 & 0.182 & 0.01543 \\
\hline 11 & 26.89 & 20.73 & 5.19 & 0.114 & 0.01261 \\
\hline 12 & 24.36 & 18.00 & 5.41 & 0.100 & 0.01178 \\
\hline 13 & 35.96 & 26.28 & 5.47 & 0.120 & 0.01258 \\
\hline 14 & 21.61 & 20.00 & 4.32 & 0.175 & 0.01622 \\
\hline 15 & 31.33 & 19.34 & 6.48 & 0.175 & 0.01366 \\
\hline$A$ & 29.82 & 21.89 & 5.45 & 0.300 & 0.01868 \\
\hline D & 33.40 & 23.00 & 5.81 & 0.238 & 0.01630 \\
\hline Mean & & & & 0.185 & \\
\hline
\end{tabular}

Table III

Mean parameters used to calculate the friction factors

\begin{tabular}{|l|c|c|c|c|c|}
\hline Point & $\boldsymbol{A}\left(\mathbf{m}^{2}\right)$ & $\operatorname{Per}(\mathbf{m})$ & $\boldsymbol{D}_{\boldsymbol{h}}(\mathbf{m})$ & $\boldsymbol{e}(\mathbf{m})$ & $\boldsymbol{f}$ \\
\hline A & 40.03 & 27.49 & 5.82 & 0.090 & 0.01102 \\
1 & 30.29 & 21.83 & 5.55 & 0.106 & 0.01193 \\
B & 25.47 & 21.17 & 4.81 & 0.062 & 0.01033 \\
C & 25.60 & 20.93 & 4.89 & 0.056 & 0.00991 \\
D & 34.50 & 26.23 & 5.26 & 0.048 & 0.00918 \\
4 & 20.79 & 18.37 & 4.53 & 0.055 & 0.01012 \\
I & 31.02 & 22.97 & 5.40 & 0.063 & 0.00999 \\
G & 38.28 & 27.44 & 5.58 & 0.052 & 0.00924 \\
R & 32.83 & 22.62 & 5.81 & 0.106 & 0.01173 \\
H & 49.45 & 29.66 & 6.67 & 0.114 & 0.01144 \\
11 & 27.37 & 20.72 & 5.28 & 0.120 & 0.01275 \\
12 & 34.91 & 23.95 & 5.83 & 0.117 & 0.01214 \\
V & 19.49 & 17.84 & 4.37 & 0.095 & 0.01254 \\
K & 28.64 & 20.92 & 5.48 & 0.158 & 0.01402 \\
L & 32.84 & 27.81 & 4.72 & 0.066 & 0.01063 \\
M & 30.85 & 21.67 & 5.69 & 0.163 & 0.01401 \\
N & 47.80 & 29.47 & 6.49 & 0.153 & 0.01293 \\
9 & 29.98 & 23.13 & 5.18 & 0.162 & 0.01450 \\
8 & 26.32 & 20.92 & 5.03 & 0.210 & 0.01644 \\
Mean & & & & 0.105 & \\
\hline
\end{tabular}

mean roughness values in Mine1 and Mine2, 0.185 and 0.105 respectively. This fact is, among other factors explained below, because of the differences in the exploitation method.

A comparison of the friction factors between both mines and the values reported in the literature can be useful to know the variability and concordance of the results. Table $\mathrm{V}$ displays the mean friction factors from all the points in Mine1 and Mine2 according to the season.

Although the values are quite similar, the friction factors from Mine2 are lower in all seasons than those in Mine1, with an average difference of $23.4 \%$. Thus, Mine 2 offers better conditions for the air to flow in terms of friction within the drift. However, there are other features that could influence the flow, such as obstacles or directional changes.

Figure 1 compares the seasonal variations in the friction factors in each mine. As can be seen, the trends are quite similar, with higher values in the spring and autumn than in

Table II

Mean friction factors and standard deviation in Mine1 (Bascompta, Sanmiquel, and Oliva, 2014)

\begin{tabular}{|c|c|c|c|c|c|c|}
\hline Point & Spring $k\left(k g / m^{3}\right)$ & Summer $k\left(k g / m^{3}\right)$ & Autumn $k\left(\mathrm{~kg} / \mathrm{m}^{3}\right)$ & Winter $k\left(k g / m^{3}\right)$ & Average $k\left(\mathrm{~kg} / \mathrm{m}^{3}\right)$ & Standard deviation $k\left(\mathrm{~kg} / \mathrm{m}^{3}\right)$ \\
\hline 0 & 0.01163 & 0.01134 & 0.01168 & 0.01184 & 0.01162 & 0.00021 \\
\hline 1 & 0.00821 & 0.00801 & 0.00822 & 0.00838 & 0.00820 & 0.00015 \\
\hline 2 & 0.00835 & 0.00848 & 0.00835 & 0.00853 & 0.00843 & 0.00009 \\
\hline 3 & 0.00794 & 0.00778 & 0.00787 & 0.00802 & 0.00790 & 0.00010 \\
\hline 4 & 0.00781 & 0.00796 & 0.00781 & 0.00796 & 0.00788 & 0.00009 \\
\hline 5 & 0.00743 & 0.00701 & 0.00750 & 0.00739 & 0.00733 & 0.00022 \\
\hline 6 & 0.00876 & 0.00872 & 0.00875 & 0.00933 & 0.00889 & 0.00029 \\
\hline 7 & 0.00860 & 0.00856 & 0.00857 & 0.00856 & 0.00857 & 0.00002 \\
\hline 8 & 0.00894 & 0.01014 & 0.00900 & 0.00940 & 0.00937 & 0.00055 \\
\hline 9 & 0.00947 & 0.00787 & 0.00952 & 0.00900 & 0.00896 & 0.00077 \\
\hline 10 & 0.00890 & 0.00890 & 0.00900 & 0.00893 & 0.00893 & 0.00005 \\
\hline 11 & 0.00735 & 0.00729 & 0.00738 & 0.00732 & 0.00733 & 0.00004 \\
\hline 12 & 0.00690 & 0.00686 & 0.00677 & 0.00677 & 0.00682 & 0.00007 \\
\hline 13 & 0.00798 & 0.00855 & 0.00803 & 0.00821 & 0.00819 & 0.00026 \\
\hline 14 & 0.00956 & 0.00956 & 0.00963 & 0.00956 & 0.00958 & 0.00003 \\
\hline 15 & 0.00758 & 0.00694 & 0.00821 & 0.00759 & 0.00758 & 0.00052 \\
\hline$A$ & 0.01081 & - & 0.01207 & 0.01088 & 0.01125 & 0.00071 \\
\hline$D$ & 0.00956 & - & 0.00972 & 0.00960 & 0.00963 & 0.00009 \\
\hline
\end{tabular}




\section{Ventilation friction factor determination and comparison: Two case studies of potash mining}

\begin{tabular}{|c|c|c|c|c|c|c|}
\hline Point & Spring $k\left(\mathbf{k g} / \mathbf{m}^{3}\right)$ & Summer $k\left(\mathrm{~kg} / \mathrm{m}^{3}\right)$ & Autumn $k\left(\mathrm{~kg} / \mathrm{m}^{3}\right)$ & Winter $k\left(\mathrm{~kg} / \mathrm{m}^{3}\right)$ & Average $k\left(\mathrm{~kg} / \mathrm{m}^{3}\right)$ & Standard deviation \\
\hline A & 0.00655 & 0.00665 & 0.00664 & 0.00661 & 0.00661 & 0.00005 \\
\hline 1 & 0.00709 & 0.00686 & 0.00720 & 0.00716 & 0.00708 & 0.00015 \\
\hline B & 0.00614 & 0.00594 & 0.00623 & 0.00620 & 0.00613 & 0.00013 \\
\hline c & 0.00589 & 0.00570 & 0.00598 & 0.00595 & 0.00588 & 0.00012 \\
\hline D & 0.00546 & 0.00555 & 0.00554 & 0.00551 & 0.00551 & 0.00004 \\
\hline 4 & 0.00601 & 0.00582 & 0.00610 & 0.00607 & 0.00600 & 0.00013 \\
\hline I & 0.00594 & 0.00633 & 0.00603 & 0.00600 & 0.00607 & 0.00017 \\
\hline G & 0.00549 & 0.00531 & 0.00557 & 0.00554 & 0.00548 & 0.00012 \\
\hline $\mathrm{R}$ & 0.00697 & 0.00675 & 0.00708 & 0.00704 & 0.00696 & 0.00015 \\
\hline $\mathrm{H}$ & 0.00680 & 0.00658 & 0.00690 & 0.00687 & 0.00679 & 0.00014 \\
\hline 11 & 0.00758 & 0.00733 & 0.00769 & 0.00765 & 0.00756 & 0.00016 \\
\hline 12 & 0.00794 & 0.00699 & 0.00733 & 0.00729 & 0.00739 & 0.00040 \\
\hline V & 0.00745 & 0.00721 & 0.00756 & 0.00752 & 0.00743 & 0.00016 \\
\hline $\mathrm{K}$ & 0.00833 & 0.00806 & 0.00845 & 0.00841 & 0.00831 & 0.00018 \\
\hline L & 0.00632 & 0.00611 & 0.00641 & 0.00638 & 0.00631 & 0.00013 \\
\hline M & 0.00832 & 0.00805 & 0.00844 & 0.00840 & 0.00830 & 0.00018 \\
\hline $\mathrm{N}$ & 0.00769 & 0.00744 & 0.00776 & 0.00776 & 0.00766 & 0.00015 \\
\hline 9 & 0.00862 & 0.00834 & 0.00874 & 0.00870 & 0.00860 & 0.00018 \\
\hline 8 & 0.00978 & 0.00946 & 0.00992 & 0.00987 & 0.00976 & 0.00021 \\
\hline
\end{tabular}

Table $V$

Comparison of the friction factors in each mine

\begin{tabular}{|l|c|c|c|c|c|c|}
\hline & Spring $\boldsymbol{k}\left(\mathbf{k g} / \mathbf{m}^{3}\right)$ & Summer $\boldsymbol{k}\left(\mathbf{k g} / \mathbf{m}^{3}\right)$ & Autumn $\boldsymbol{k}\left(\mathbf{k g} / \mathbf{m}^{\mathbf{3}}\right)$ & Winter $\boldsymbol{k}\left(\mathbf{k g} / \mathbf{m}^{\mathbf{3}}\right)$ & Average $\boldsymbol{k}\left(\mathbf{k g} / \mathbf{m}^{\mathbf{3}}\right)$ & Standard deviation \\
\hline Mine1 & 0.00865 & 0.00837 & 0.00878 & 0.00874 & 0.00869 & 0.00024 \\
Mine2 & 0.00707 & 0.00687 & 0.00714 & 0.00710 & 0.00704 & 0.00016 \\
Difference (\%) & 22.4 & 21.9 & 23.1 & 23.0 & 23.4 & 52.4 \\
\hline
\end{tabular}

Table VI

Percentage difference between the values obtained and the values from the literature

\begin{tabular}{|c|c|c|c|c|}
\hline \multirow[t]{2}{*}{ Airway type } & \multirow[t]{2}{*}{ Potash mine value } & \multicolumn{3}{|c|}{ Difference (\%) } \\
\hline & & Prosser and Wallace (2002) & McPherson (1993) & Hartman et al. (1997) \\
\hline Rectangular airway, clean & 0.0076 & -1.32 & 18.42 & 5.26 \\
\hline Rectangular airway, some irregularities & 0.00762 & 14.17 & 18.11 & 19.42 \\
\hline Mine drift & 0.01215 & -27.57 & -1.23 & 121.40 \\
\hline Mine ramp & 0.00823 & 40.95 & - & 260.87 \\
\hline
\end{tabular}

Season friction factor $\left(\mathrm{kg} / \mathrm{m}^{3}\right)$

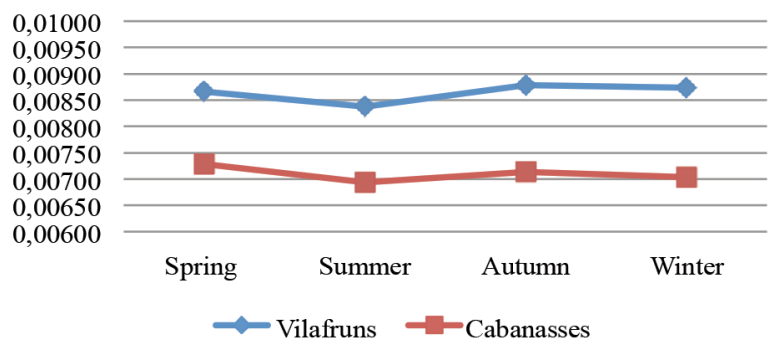

Figure 1-Seasonal variations in friction factor

the winter and summer. This behaviour could be due to the important variations in temperature and humidity in the spring and autumn, even within the same day, which would affect the characteristics of the air and, therefore, the stability of the roofs and walls in the airways, changing the roughness and subsequently the friction factor values.
The difference in standard deviation between the two mines could be due to several factors, either intrinsic to the mines or related to operational characteristics such as airway maintenance, which is quite different in each mine.

Since there is no bibliographic information concerning underground potash mining, the values obtained were compared 


\section{Ventilation friction factor determination and comparison: Two case studies of potash mining}

with the current parameters from coal and metal mines (Table VI). Comparison from the 'Mine ramp' airway type , in Table VI, has only been performed with values from Mine1, because there is no ramp in Mine2. The other values were obtained using data from both mines. Table VI shows the percentage variation from values gathered by Bascompta et al. (2014) and from the current paper. As it can be seen, there is an important difference in some airway types, such as 'Mine ramp', but there is a significant correlation in most of the types of airways.

\section{Validation}

Tthe friction factors obtained for each season (Tables II and IV) were used to model both mines by means of the ventilation software VnetPro, and a comparison between the airflow modelled and the in situ measures was performed, either in Mine2 or Mine1.

\section{Mine1}

Four different models, corresponding to the four seasons of the year, with their friction factors, have been constructed. Consistent results were achieved in all the cases, with the only appreciable variations in some leakages, in percentage terms. This is a standard behaviour in mine ventilation models, where leakages can cause high percentage differences. Hence, the airflow is within just a few cubic metres in these cases, without affecting the soundness of the model. Besides, a 10\% difference can be considered acceptable in standard control points (Belle, 2013). Table VII displays the absolute and percentage variations between the measured and modelling control points. The comparison is done using the average variation in each mine.

\section{Mine2}

The same analysis is shown in Table VIII for Mine2. Once more, only airflows from leakages show considerable differences between the model and the real values.

\section{Conclusions}

Characteristic friction factors were determined in two potash

\section{Table VII}

\section{Comparison between measured and modelling results in Mine1}

\begin{tabular}{|c|c|c|c|}
\hline Control point & Percentage variation (\%) & Absolute variation $\left(\mathrm{m}^{3} / \mathrm{s}\right)$ & Description \\
\hline 0 & 0.79 & 1.41 & Entry ventilation circuit \\
\hline 1 & 0.67 & 1.18 & Intake after the main fan \\
\hline 2 & 2.99 & 1.03 & Leakage 1 \\
\hline 3 & 2.17 & 3.03 & Intake intermediate position \\
\hline 4 & 1.31 & 1.51 & Leakage 2 \\
\hline 5 & 17.62 & 2.68 & Entry workshop 1 \\
\hline 6 & 5.55 & 1.50 & Leakage 3 \\
\hline 7 & 22.34 & 3.50 & Leakage 4 \\
\hline 8 & 27.38 & 3.45 & Leakage 5 \\
\hline 9 & 2.85 & 2.65 & Workshop north zone \\
\hline 10 & 6.34 & 7.06 & Intake south zone \\
\hline 11 & 2.37 & 2.96 & Intake 2 south zone \\
\hline 12 & 1.51 & 2.14 & Return \\
\hline 13 & 2.53 & 4.29 & Ramp and exit \\
\hline 14 & 26.88 & 2.29 & Leakage 6 \\
\hline$A$ & 9.61 & 6.76 & Leakages workshop $\mathrm{N}$ and 1 \\
\hline $\mathrm{D}$ & 15.16 & 3.47 & Leakage 7 \\
\hline
\end{tabular}

\section{Table VIII}

\section{Comparison between measured and modelling results in Mine2}

\begin{tabular}{|c|c|c|c|}
\hline Control point & Percentage variation (\%) & Absolute variation $\left(\mathrm{m}^{3} / \mathrm{s}\right)$ & Description \\
\hline A & 8.83 & 18.4 & Entry ventilation circuit \\
\hline B & 9.69 & 1.51 & Leakage 1 \\
\hline C & 3.36 & 1.81 & Storage connection \\
\hline D & 0.63 & 1.21 & Main intake \\
\hline G & 8.62 & 6.13 & Beginning north zone \\
\hline H & 3.30 & 2.44 & Intermediate north zone \\
\hline I & 4.55 & 4.06 & Beginning east zone \\
\hline K & 6.45 & 2.22 & Entry workshop 1 \\
\hline L & 6.33 & 5.19 & Intermediate east zone \\
\hline M & 4.19 & 1.00 & Entry workshop 2a \\
\hline N & 13.60 & 8.59 & Entry workshop $2 b$ \\
\hline $\mathrm{R}$ & 296.50 & 8.48 & Leakage 2 \\
\hline 1 & 11.62 & 2.45 & Leakage 3 \\
\hline 4 & 5.29 & 8.34 & Return connection zones \\
\hline 8 & 0.58 & 0.62 & Return workshop 1 \\
\hline 9 & 5.79 & 6.21 & Return workshop 2 \\
\hline 11 & 3.97 & 2.94 & Return north zone ending \\
\hline 12 & 3.75 & 2.67 & Return north zone intermediate \\
\hline V & 2.45 & 5.11 & Exit \\
\hline
\end{tabular}




\section{Ventilation friction factor determination and comparison: Two case studies of potash mining}

mines using the room-and-pillar method. These values can be useful for mine ventilation planning, which usually relies on $k$-factor values to estimate the resistance of planned airways. The average and seasonal friction factor values have been assessed as suitable to create a ventilation model, depending on the climatic conditions where the mine is situated. However, more data from other similar operations is recommended to increase the accuracy.

Roughness of the airways varies slightly depending on the ventilation circuit zone and mine. Consistent differences in the friction factors over the year are found in Mine1 and Mine2, but these are too small to influence the model. In most cases in both mines, except for some leakages, the difference between the measured and modelled airflows is less than $10 \%$.

After observing all the features from the case studies, it can be concluded that the roughness of the airways basically depends on three factors:

(1) The exploitation method and maintenance of the airways

(2) The nature of the deposit, which has certain deformable properties that affect the shape of the drifts

(3) The outside climatic conditions (temperature and humidity) have been proved to be significant factors in terms of roughness variations.

\section{Acknowledgments}

This work was supported by the ICL Chair in Mining Sustainability (UPC). The authors would like to thank the staff of both mines for their willingness and contributions to the results.

\section{References}

Alymenko, N.I. 2012. Aerodynamic parameters of ventilating passages joined-up with the main mine fan. Journal of Mining Science, vol. 47, no. 6. pp. 814-823.

Bascompta, M., SANmiquel, L., and Oliva, J. 2015. Ventilation management system for underground environments. Tunnelling and Underground Space Technology, vol. 50. pp. 516-522.

Bascompta, M., Sanmiquel, L., and Oliva, J. 2014. Determination of the friction factors in potash mines. Journal of Mining Science, vol. 50, no. 5. pp. 953-958.

BELLE, B. 2013. Real-time air velocity monitoring in mines: A quintessential design parameter for managing major mine health and safety hazards. Proceedings of the 13th Coal Operators' Conference, University of Wollongong. Australasian Institute of Mining and Metallurgy, Melbourne. pp. 184-198.

Develo, E., Pillalamarry, M., and Garab, E. 2016. Improving the ventilation system at Rosh Pinah zinc mine. Journal of the Southern African Institute of Mining and Metallurgy, vol. 116, no. 4. pp. 301-305.

Diego, I., Torno, S., Toraño, J., Menéndez, M., and Gent, M. 2011. A practical use of $\mathrm{CDF}$ for ventilation of underground works. Tunnelling and Underground Space Technology, vol. 26, no. 1. pp. 189-200.

Du Plessis, J.J.L., Marx, W.M., and Nell, C. 2014. Efficient use of energy in the ventilation and cooling of mines. Journal of the Southern African Institute of Mining and Metallurgy, vol. 114, no. 12. pp. 1033-1037.

Duckworth, I., Loomis, I., and Prosser, B. 2012. Fifteen years of resistance data collected at Freeport Indonesia. Proceedings of the 14th US/North American Mine Ventilation Symposium, Salt Lake City, UT. Society for Mining, Metallurgy and Exploration, Littleton, CO. pp. 161-166.

Duckworth, I. and Prosser, B. 1997. Analysis of the data obtained from ventilation studies of longwall panels. Proceedings of the 6 th International Mine
Ventilation Congress, Pittsburgh, PA. Society for Mining, Metallurgy and Exploration, Littleton, CO. pp. 223-229.

FYTAS, K. and GAGNON, C. 2008. A database of ventilation friction factors for Quebec underground mines. Proceedings of the 14th US/North American Mine Ventilation Symposium, Salt Lake City. Society for Mining, Metallurgy and Exploration, Littleton, CO. pp. 615-622.

HaLl, C.J. 1981. Mine Ventilation Engineering. Society for Mining, Metallurgy and Exploration Inc., Littleton, CO. pp. 62-72.

Hartman, H., Mutmansky, J., Ramani, R., and Wang, Y. 1997. Mine Ventilation and Air Conditioning. 3th edn. Wiley, Vancouver.

Hurtado, J.P., Díaz, N., Acuña, E.I., Fernández, J., Díaz, N., Acuña, E.I., and Fernández, J. 2014. Shock losses characterization of ventilation circuits for block caving production levels. Tunnelling and Underground Space Technology, vol. 41, no. 1. pp. 88-94.

JADE, R.K. and SASTRY, B.S. 2008. An experimental and numerical study of two-way splits and junction in mine airways. Proceedings of the 12th US/ North American Mine Ventilation Symposium, Reno, NV. Society for Mining, Metallurgy and Exploration, Littleton, CO.

Kazakov, B.P., Shalimov, A.V., and KiRYaKov, A.S. 2013. Energy-saving mine ventilation. Journal of Mining Science, vol. 49, no. 3. pp. 475-481.

Kharkar, R., Stefanko, R., and Ramani, R.V. 1974. Analysis of leakage and friction factors in coal mine ventilation systems. Special Research Report no. SR-99. Pennsylvania Department of Commerce, Harrisburg, PA.

McElroy, G. 1935. Engineering Factors in the Ventilation of Metal Mines. US Bureau of Mines.

McPherson, M.J. 1993. Subsurface ventilation and environmental engineering. Mine Ventilation Services Inc., Clovis, CA.

MEYER, C. 1998. Determining the friction factors for underground colliery bord and pillar working. Safety in Mines Research Advisory Committee, Johannesburg.

Montecinos, C. and Wallace, K. 2010. Equivalent roughness for pressure drop calculations in mine ventilation. Proceedings of the 13th US/North American Mine Ventilation Symposium, Sudbury, Ontario. Society for Mining, Metallurgy and Exploration, Littleton, CO. pp. 225-230.

Prosser, B. and Wallace, K. 2002. Practical values of friction factors. Mine Ventilation Service, Inc., Clovis, CA.

Prosser, B. and Wallace, K. 1999. Practical values of friction factors. Proceedings of the sth US Mine Ventilation Symposium, Rolla, MO. Society for Mining, Metallurgy and Exploration, Littleton, CO. pp. 691-696.

Sasmito, A.P., Birgersson, E., Ly, H.C., and Mujumdar, A.S. 2013. Some approaches to improve ventilation system in underground coal mines environment - A computational fluid dynamic study. Tunnelling and Underground Space Technology, vol. 34. pp. 82-95.

Shalimov, A.V. 2011. Numerical modelling of air flows in mines under emergency state ventilation. Journal of Mining Science, vol. 47. pp. 807-813.

WALA, A.M. 1991. Studies of friction factor for Kentucky's coal mines. Proceedings of the 5th US Mine Ventilation Symposium, Morgantown, WV. Society for Mining, Metallurgy and Exploration, Littleton, CO. pp. 675-684. 